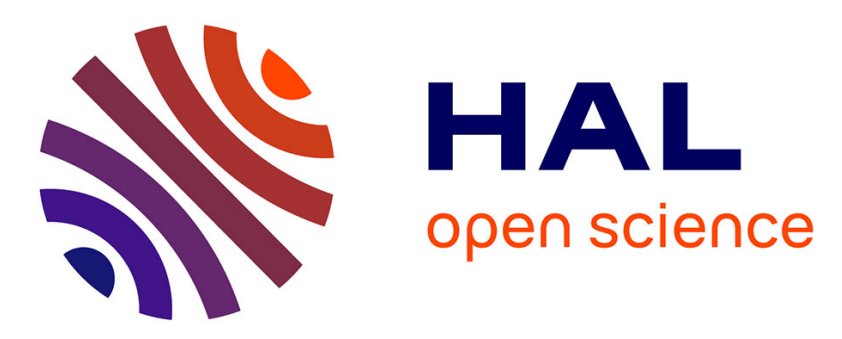

\title{
Grafting of maleic anhydride on polypropylene by reactive extrusion: Effect of maleic anhydride and peroxide concentrations on reaction yield and products characteristics
}

Françoise Berzin, Jean-Jacques Flat, Bruno Vergnes

\section{To cite this version:}

Françoise Berzin, Jean-Jacques Flat, Bruno Vergnes. Grafting of maleic anhydride on polypropylene by reactive extrusion: Effect of maleic anhydride and peroxide concentrations on reaction yield and products characteristics. Journal of Polymer Engineering, 2013, 33 (8), pp.673-682. 10.1515/polyeng2013-0130 . hal-00918914

HAL Id: hal-00918914

https://hal-mines-paristech.archives-ouvertes.fr/hal-00918914

Submitted on 16 Dec 2014

HAL is a multi-disciplinary open access archive for the deposit and dissemination of scientific research documents, whether they are published or not. The documents may come from teaching and research institutions in France or abroad, or from public or private research centers.
L'archive ouverte pluridisciplinaire HAL, est destinée au dépôt et à la diffusion de documents scientifiques de niveau recherche, publiés ou non, émanant des établissements d'enseignement et de recherche français ou étrangers, des laboratoires publics ou privés. 
Françoise Berzin*, Jean-Jacques Flat and Bruno Vergnes

\section{Grafting of maleic anhydride on polypropylene by reactive extrusion: effect of maleic anhydride and peroxide concentrations on reaction yield and products characteristics}

\begin{abstract}
A series of polypropylenes (PPs) grafted with maleic anhydride (MA), prepared by reactive extrusion in a twin screw extruder with different contents of peroxide and MA, was characterized. For each sample, the amount of grafted MA, the molecular weight distribution, the viscoelastic properties in small amplitude oscillatory shear and the transition temperatures and enthalpies were measured. The respective influence of initial MA and peroxide concentrations on these parameters was characterized. In particular, it was shown that the rheological properties are only controlled by the molecular weight, whatever the way it has been obtained, by varying either MA content or peroxide concentration. Moreover, it is clearly shown that the presence of MA tends to enhance the PP degradation due to the peroxide.
\end{abstract}

Keywords: grafting; maleic anhydride; polypropylene; reactive extrusion; rheology.

*Corresponding author: Françoise Berzin, University of Reims Champagne-Ardenne, UMR614 INRA FARE, F-51100 Reims, France, e-mail: francoise.berzin@univ-reims.fr

Jean-Jacques Flat: Arkema, Cerdato, BP 27, Serquigny, France Bruno Vergnes: MINES ParisTech, CEMEF, UMR CNRS 7635, BP 207 F-06904 Sophia-Antipolis, France

\section{Introduction}

Many studies have been devoted to the grafting of maleic anhydride (MA) onto polypropylene (PP). As PP is a nonpolar polymer, it has limited interactions with other products and the grafting of MA functions allows new and interesting functionalities to be obtained, such as adhesion or compatibilization [1]. Grafting was initially conducted in solution [2-4] or in batch in the melt state [2, 5-8]. However, it is now common to produce grafted PP by reactive extrusion, using twin screw extruders as continuous reactors [9-21]. A major advantage of the reactive extrusion process is avoidance of the use of solvent, but the high temperatures encountered in extrusion can also lead to secondary reactions, like $\beta$-scissions for the PP [22, 23]. Moreover, in such conditions, the reaction yields are generally lower than those obtained in solution [1].

Despite the number of publications on the topic, there are still some discussions on particular reactional mechanisms [11, 24-27]. However, in a general way and according to Nachtigall et al. [28], we can propose the following simplified mechanism: the free radicals generated by the peroxide decomposition lead by hydrogen abstraction to tertiary alkyl polymer radicals. It results in a depropagation of the PP chain by $\beta$-scission, leading to a shorter chain and a new secondary alkyl polymer radical. A molecule of MA can then be grafted (in the form of succinic anhydride) on a macroradical, either before the $\beta$-scission, or issued from the $\beta$-scission. Finally, a stable grafted polymer is obtained by hydrogen abstraction. The reactions of PP depropagation can be accompanied by many secondary reactions, like recombination between free radicals or macroradicals, termination by combination or dismutation, and intramolecular and intermolecular transfer. Moreover, the presence of MA molecules can induce supplementary reactions, also leading to polymer macroradicals which can enhance $\beta$-scissions $[1,13]$.

When grafting MA onto $P P$ by reactive extrusion, it is of vital importance to master the impact of MA and peroxide concentration on both the reaction efficiency (quantity of grafted MA) and the properties of the resulting grafted PP (PP-g-MA), especially the viscous behavior. If the increase of peroxide concentration is assumed to reduce molecular weight and viscosity $[7,10]$, the role of MA concentration is more controversial: for Bettini and Agnelli [6], melt flow index (MFI) decreases with MA concentration, when it increases and passes through a maximum for Ghahari et al. [29]. Similarly, complex viscosity is found to increase [7] or to decrease [29] with MA concentration. Moreover, a detailed and systematic investigation of the rheological behavior of PP grafted with different MA and peroxide concentrations is still missing. Thus, the objectives 
of the present paper are not to present new insights on the grafting mechanisms, but to investigate in detail the role of peroxide and MA concentrations on reaction yield, molecular weight distribution, rheological properties and crystallization of a series of PP-g-MA prepared by reactive extrusion. Our intention is to provide an experimental database which could be useful for readers involved in the preparation of grafted $\mathrm{PP}$ by reactive extrusion.

\section{Experimental section}

\subsection{Materials}

We used a PP homopolymer provided by Appryl (PP 3050 BN 1, Total Petrochemicals, La Défense, France). It had a melt index of $4.5 \mathrm{~g} / 10 \mathrm{~min}\left(2.16 \mathrm{~kg} / 230^{\circ} \mathrm{C}\right)$. The peroxide was 2,5-dimethyl-2,5-bis-(t-butylperoxy)-hexane (DHBP), provided by Arkema (Luperox 101, Arkema, Columbes, France). It was used in the solid form, on a powder support (DHBP powder at $7.5 \mathrm{wt} \%$ mixed with PP powder). MA was obtained from Crystal Man (NOF Corp., Tokyo, Japan). It was used as a powder, previously mixed with the one containing the peroxide.

\subsection{Reactive extrusion}

Grafting of MA onto PP was conducted on a laboratory corotating twin screw extruder Leistritz 30-34 (diameter $34 \mathrm{~mm}$, length to diameter ratio 32.6), equipped with nine barrel elements.

The PP pellets and the blend of powders containing MA and DHBP were introduced in the first barrel using two volumetric feeders. Melting took place in barrel 3, with two blocks of kneading discs staggered at $-30^{\circ}$ and $30^{\circ}$. Then, the reaction zone was made of screw transport elements and three blocks of kneading discs in barrels 4, 5 and 6 , with staggering angles of, respectively, $90^{\circ}, 30^{\circ}$ and $30^{\circ}$. Devolatilization took place in barrel 7 , to remove any residual peroxide. The barrel temperature increased from $190^{\circ} \mathrm{C}$ to $250^{\circ} \mathrm{C}$ between zones 1 and 7, and decreased down to $180^{\circ} \mathrm{C}$ at the die. At the die exit, extrudates were cooled down in water and dried before pelletizing.

All of the experiments were conducted in the same conditions, with a total flow rate of $10 \mathrm{~kg} / \mathrm{h}$ and a screw speed of $75 \mathrm{rpm}$. The peroxide concentration was varied between $250 \mathrm{ppm}$ and $3000 \mathrm{ppm}$ and, for each peroxide concentration, the MA amount was varied between $0.1 \mathrm{wt} \%$ and $2 \mathrm{wt} \%$.

\subsection{Grafting quantification}

Bettini and Agnelli [30] have compared different methods to evaluate the grafting rate of MA onto $\mathrm{PP}$, like potentiometric titration, infrared spectroscopy [30], and gravimetry. They showed the necessity to purify the samples before analysis, to remove any unreacted MA. In our case, PP-g-MA samples were dissolved in hot xylene and precipitated with acetone. Then, they were characterized by infrared spectroscopy, by considering two specific peaks [31]: the first one at $1790 \mathrm{~cm}^{-1}$ concerns the carbonyl groups, and the second one at $1167 \mathrm{~cm}^{-1}$ concerns the $\mathrm{CH}_{3}$ groups. The ratio of these peak areas is the carbonyl index (Index $=A_{1790} / A_{1167}$ ), which can be related to the percentage of grafted MA using a calibration curve [26, 32]. The grafting yield (GY) can then be defined as the ratio of grafted MA ([MA $]_{\mathrm{g}}$, expressed in wt $\%$ ) to introduced amount $[\mathrm{MA}]_{\mathrm{i}}$ :

$$
\mathrm{GY}=\frac{[\mathrm{MA}]_{\mathrm{g}}}{[\mathrm{MA}]_{\mathrm{i}}} .
$$

\subsection{Size exclusion chromatography}

The molecular weight distribution of the different samples was obtained by size exclusion chromatography (SEC), performed at Centre de Recherches de Lacq (CRL), France, from Arkema company. The samples were dissolved at $145^{\circ} \mathrm{C}$, at a polymer concentration of $0.8 \mathrm{~g} / \mathrm{l}$ in the 1,2,4-trichlorobenzene, which was used as a solvent with the addition of an antioxidant to prevent any degradation.

\subsection{Rheological characterization}

MFI was measured at $190^{\circ} \mathrm{C}$ under a load of $1 \mathrm{~kg}$. Rheological measurements were conducted in small amplitude oscillatory shear on a parallel plate rheometer (Stress Tech, Reologica, Bordentown, NJ, USA). Samples were prepared from extruded pellets by compression at $210^{\circ} \mathrm{C}$ under $20 \mathrm{MPa}$ for $60 \mathrm{~s}$, followed by a cooling under pressure to ambient temperature. Measurements were carried out in the linear viscoelastic regime at three temperatures $\left(180^{\circ} \mathrm{C}, 200^{\circ} \mathrm{C}\right.$ and $\left.220^{\circ} \mathrm{C}\right)$, in a range of angular frequencies between $100 \mathrm{rad} / \mathrm{s}$ and $0.1 \mathrm{rad} / \mathrm{s}$.

\subsection{Differential scanning calorimetry}

Some samples (250 ppm-3000 ppm of peroxide at $0 \mathrm{wt} \%$ and $2 \mathrm{wt} \% \mathrm{MA}$, and $0 \mathrm{wt} \%$ to $2 \mathrm{wt} \% \mathrm{MA}$ at $2000 \mathrm{ppm}$ 
peroxide) were characterized in a differential scanning calorimeter (DSC), Perkin Elmer DSC 7, to define the temperatures of melting and crystallization, and the rate of crystallization. Samples were first heated during $3 \mathrm{~min}$ to the temperature of thermodynamic equilibrium (around $208^{\circ} \mathrm{C}$ ) to melt any crystalline part and obtain a reference state, and then cooled down to ambient temperature. The following cycle was then applied in the DSC: heating from $50^{\circ} \mathrm{C}$ to $210^{\circ} \mathrm{C}$ at $10^{\circ} \mathrm{C} / \mathrm{min}$, cooling from $210^{\circ} \mathrm{C}$ to $50^{\circ} \mathrm{C}$ and second heating in the same conditions.

\section{Results and discussion}

\subsection{Reaction yield}

Figure 1 shows the percentage of grafted MA $\left([\mathrm{MA}]_{\mathrm{g}}\right)$ as a function of MA concentration ([MA $]_{\mathrm{i}}$ ) for different amounts of peroxide. Generally speaking, the percentage of grafted MA increased with $[\mathrm{MA}]_{\mathrm{i}}$ and peroxide concentrations. At a low peroxide amount, $[\mathrm{MA}]_{\mathrm{g}}$ first increased, then stabilized above a value of $[\mathrm{MA}]_{\mathrm{i}}$, which is all the more high as the peroxide content is high. Cha and White [7] reported similar trends, with a maximum of grafted species for $4 \mathrm{wt} \%$ of MA. Garcia Martinez et al. [8] also presented results with a maximum of around $6.5 \mathrm{wt} \%$ of MA, but at a very high peroxide concentration (6500 ppm). Bettini and Agnelli [10] reported no influence of $[\mathrm{MA}]_{\mathrm{i}}$ on $[\mathrm{MA}]_{\mathrm{g}}$, but for $[\mathrm{MA}]_{\mathrm{i}}$ between $1.5 \mathrm{wt} \%$ and $4 \mathrm{wt} \%$ and a peroxide amount between $50 \mathrm{ppm}$ and $1000 \mathrm{ppm}$. This is what is

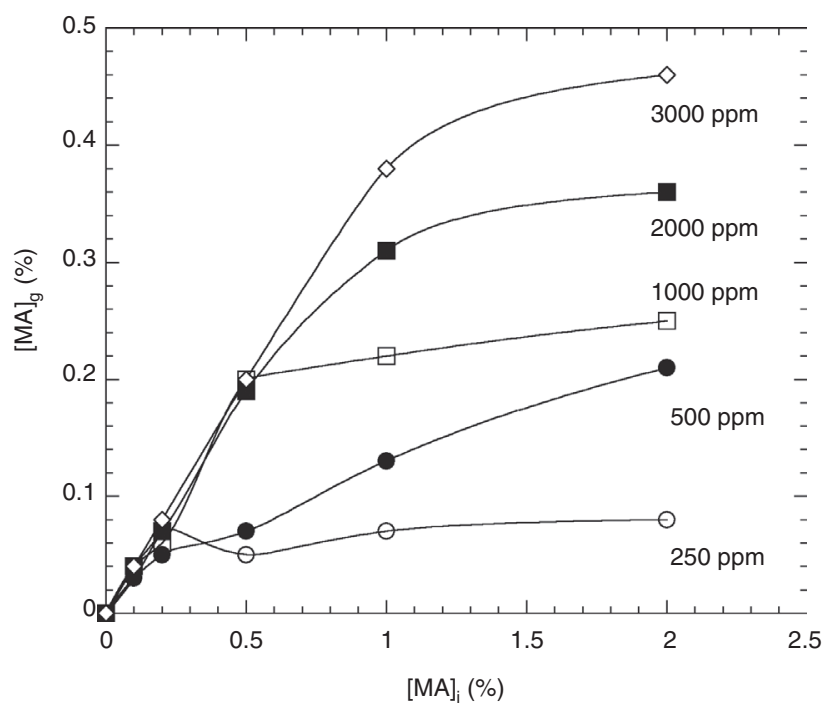

Figure 1 Evolution of percentage of grafted maleic anhydride ([MA $]_{g}$ ) as function of MA concentration ([MA $]_{\text {; }}$ ) for different amounts of peroxide (the lines are just to guide the eyes). observed in Figure 1 for these ranges of concentration. In other words, the dependence of $[\mathrm{MA}]_{\mathrm{i}}$ on $[\mathrm{MA}]_{\mathrm{g}}$ essentially depends on the range investigated for both $[\mathrm{MA}]_{i}$ and peroxide concentrations.

The influence of peroxide concentration is shown in Figure 2 for different values of $[\mathrm{MA}]_{\mathrm{i}}$. We observed different situations. At low $[\mathrm{MA}]_{\mathrm{i}}$, typically below $0.5 \mathrm{wt} \%$, the quantity of grafted MA was independent of the peroxide content. Conversely, above $1 \mathrm{wt} \%,[\mathrm{MA}]_{\mathrm{g}}$ increased linearly with peroxide concentration, as already shown by different authors $[7,8,10]$. However, the GY [Eq. (1)] always decreased when $[\mathrm{MA}]_{\mathrm{i}}$ increased and when peroxide concentration decreased (Figure 3). To summarize, the best grafting conditions $(\mathrm{GY} \approx 0.4)$ are obtained at low MA content $(<1 \%)$ and high peroxide concentration (here, above $1000 \mathrm{ppm}$ ). However, these conditions do not provide the highest $[\mathrm{MA}]_{\mathrm{g}}$. In our case, the highest value $\left([\mathrm{MA}]_{\mathrm{g}}=0.46 \%\right)$ was obtained at $2 \%$ and $3000 \mathrm{ppm}$ peroxide, for a GY of $0.23 \%$.

\subsection{Melt index and molecular weight distribution}

MFI values for the different samples are shown in Figure 4. MFI increased with peroxide content, but $[\mathrm{MA}]_{\mathrm{i}}$ also had an influence, at least above $0.5 \mathrm{wt} \%$. The presence of MA molecules enhanced PP degradation, the highest MFI being obtained at $2 \mathrm{wt} \%[\mathrm{MA}]_{\mathrm{i}}$ and 3000 ppm peroxide. In the literature, a linear increase of MFI with peroxide content is generally observed $[6,10,30]$. However,

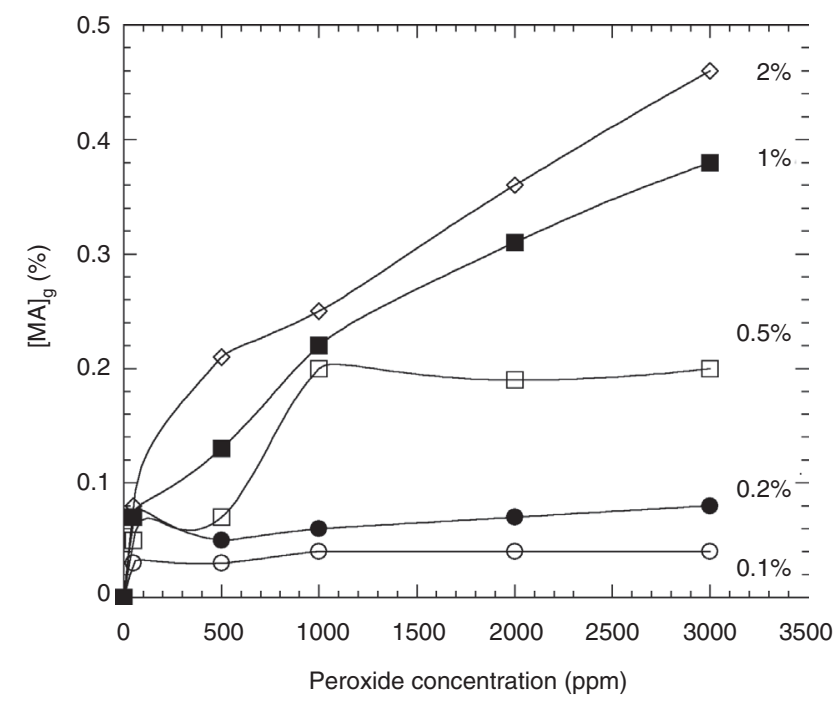

Figure 2 Evolution of percentage of grafted maleic anhydride $\left([M A]_{g}\right)$ as function of peroxide concentration for different amounts of $[M A]_{i}$ (the lines are just to guide the eyes). 


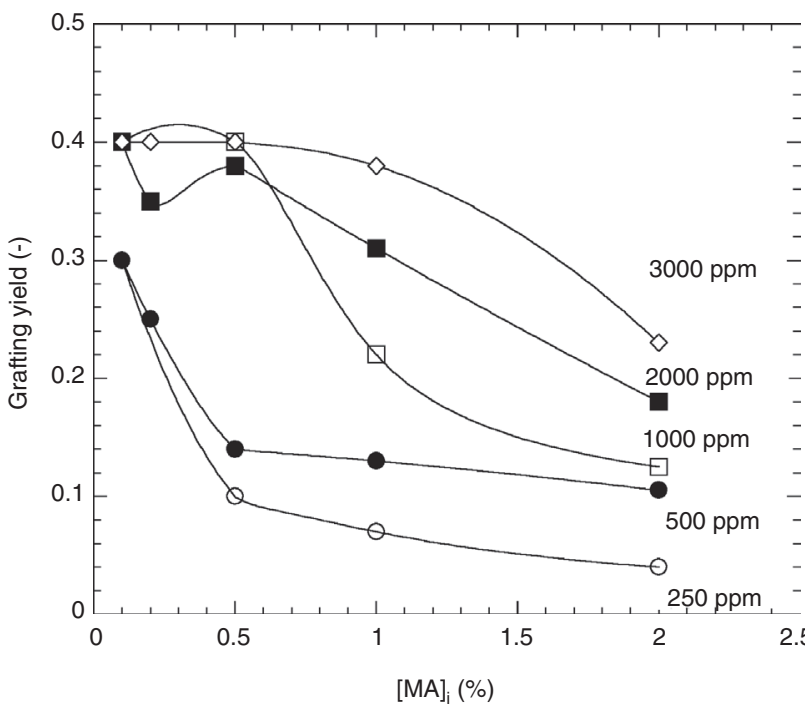

Figure 3 Evolution of grafting yield as function of $[\mathrm{MA}]_{i}$, where $M A$ is maleic anhydride, for different amounts of peroxide (the lines are just to guide the eyes).

the impact of $[\mathrm{MA}]_{\mathrm{i}}$ is not clear. At high peroxide content (8000 ppm), Ghahari et al. [29] observed an increase of MFI between $0 \mathrm{wt} \%$ and $2 \mathrm{wt} \%$, followed by a decrease up to $8 \mathrm{wt} \%$. Between $500 \mathrm{ppm}$ and $1000 \mathrm{ppm}$ peroxide, Bettini and Agnelli [10] reported a decrease followed by an increase of MFI, the minimum being around $3 \mathrm{wt} \%$ $[\mathrm{MA}]_{\mathrm{i}}$. In our case, below $500 \mathrm{ppm}$ peroxide, we observed a maximum in MFI around $1 \mathrm{wt} \%[\mathrm{MA}]_{\mathrm{i}}$, whereas, between $1000 \mathrm{ppm}$ and $3000 \mathrm{ppm}$, MFI continuously increased between $0 \mathrm{wt} \%$ and $2 \mathrm{wt} \%[\mathrm{MA}]_{\mathrm{i}}$.

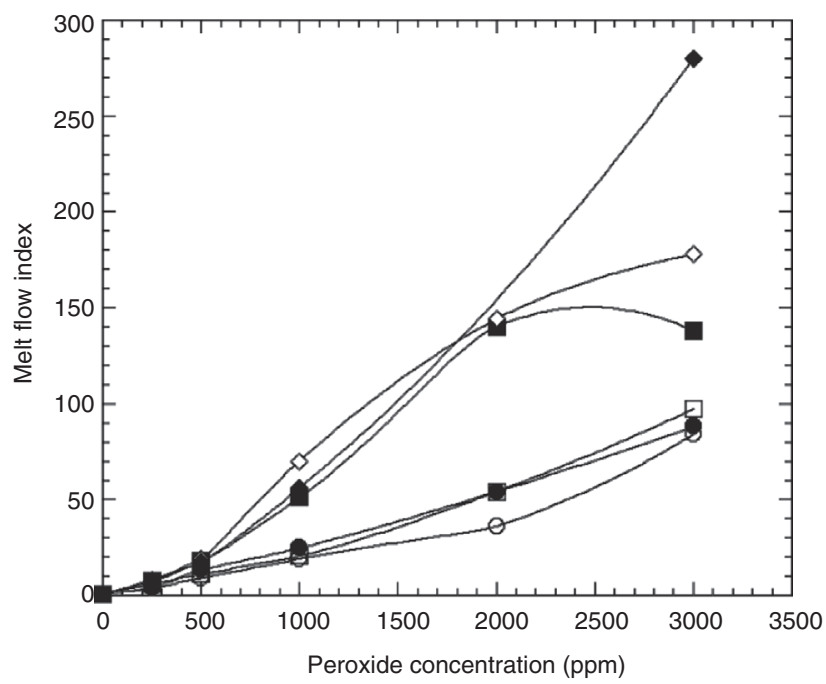

Figure 4 Evolution of melt flow index (MFI) as function of peroxide concentration for different amounts of [MA], where MA is maleic anhydride (O: $0 \%, \bullet: 0.1 \%, \square: 0.2 \%, \square: 0.5 \%, \diamond: 1 \%, \diamond: 2 \%$ ) (the lines are just to guide the eyes).

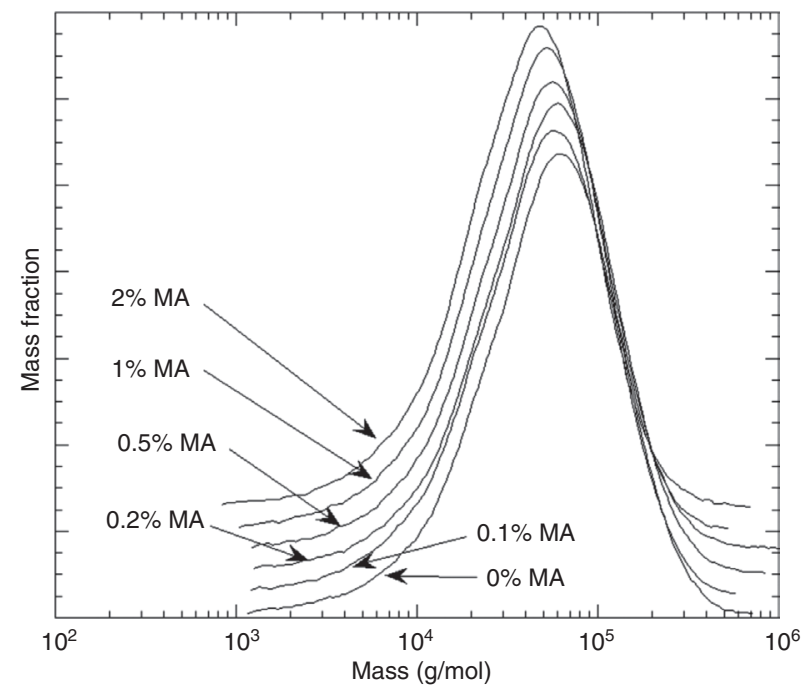

Figure 5 Molecular weight distributions for the samples with different amounts of $[M A]_{i}$, where $M A$ is maleic anhydride, at $3000 \mathrm{ppm}$ peroxide (the curves have been shifted vertically for more clarity).

Figure 5 shows the molecular weight distribution obtained by SEC for the samples with different amounts of $[\mathrm{MA}]_{\mathrm{i}}$ and $3000 \mathrm{ppm}$ peroxide.

The weight average molecular weight $\left(M_{w}\right)$ of the PP extruded without DHBP was $264,700 \mathrm{~g} / \mathrm{mol}$. We observed a clear shift of the distributions towards lower masses. $M_{w}$ decreased from 74,900 to 55,590 when [MA] $]_{i}$ increased from $0 \mathrm{wt} \%$ to $2 \mathrm{wt} \%$, and the polydispersity index remained constant, around 2.6 (for 4.8 for the PP extruded without DHBP). Figure 6 shows more precisely

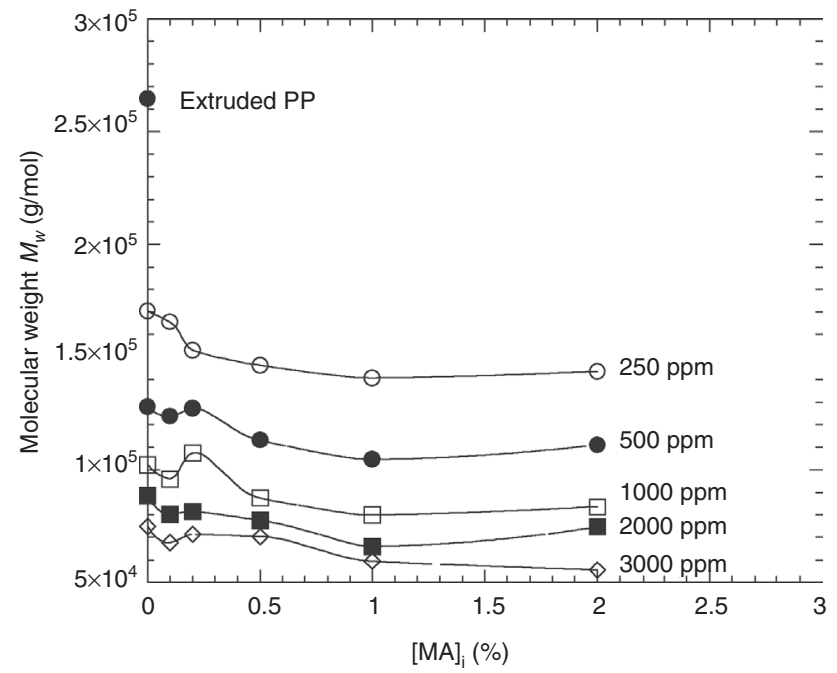

Figure 6 Evolution of molecular weight as a function of $[M A]_{i}$, where MA is maleic anhydride, for different amounts of peroxide (O: 250 ppm, •: 500 ppm, $\square: 1000$ ppm, 口: 2000 ppm, $\diamond: 3000$ $\mathrm{ppm}$ ) (the lines are just to guide the eyes). 
the change in $M_{w}$ with the percentage of introduced MA and peroxide. It is obvious that the increase of peroxide induced a strong decrease of molecular weight by $\beta$-scissions, as already observed for controlled rheology PP [33, 34]. Concerning the effect of MA, the conclusions slightly differ from what could be observed for MFI in Figure 4. Generally speaking, whatever the peroxide content, $M_{w}$ decreased when [MA] increased up to $1 \mathrm{wt} \%$, and then reached a plateau. These results confirm that a small amount of MA tends to increase PP degradation, as already observed with MFI.

In the literature, there are only a few studies on the effect of MA grafting on molecular weight distribution. Zhang et al. [25] reported a decrease of $M_{w}$ with [MA] $]_{\mathrm{i}}$, but for products obtained in solution. The same tendencies were shown by Shi et al. [11] for products prepared by reactive extrusion. On the contrary, Zhu et al. [35] obtained, by Monte Carlo simulation, an increase in number average molcular weight $M_{n}$ with [MA] $]_{i}$. A slight increase of $1 \%-2 \%$ in $M_{w}$ was also observed by Bettini and Agnelli [10], but only on two points, at $1.5 \mathrm{wt} \%$ and $4 \mathrm{wt} \% \mathrm{MA}$ and $500 \mathrm{ppm}$ and $1000 \mathrm{ppm}$ peroxide. In Figure 6, we can effectively see that $M_{w}$ could slightly increase above $1 \%$ MA for these concentrations. To summarize, we conclude that, if the molecular weight always decreases with peroxide concentration, the influence of $[\mathrm{MA}]_{\mathrm{i}}$ is less evident and probably depends on the range of concentrations and melt grafting conditions.

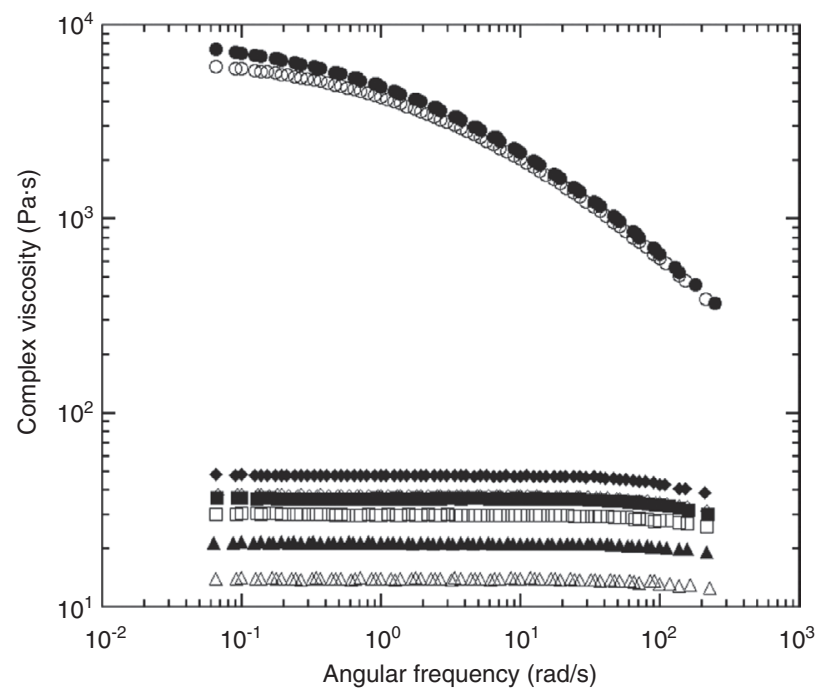

Figure 7 Evolution of complex viscosity with frequency at $3000 \mathrm{ppm}$ peroxide for different amounts of $[\mathrm{MA}]_{\mathrm{i}}$, where MA is maleic anhydride ( $: 0 \%, \diamond: 0.1 \%, \square: 0.2 \%, \square: 0.5 \%, \Delta: 1 \%, \Delta$ : $2 \%)$. For comparison, polypropylene (PP) pellets $(\bullet)$ and extruded PP (O) are also presented.

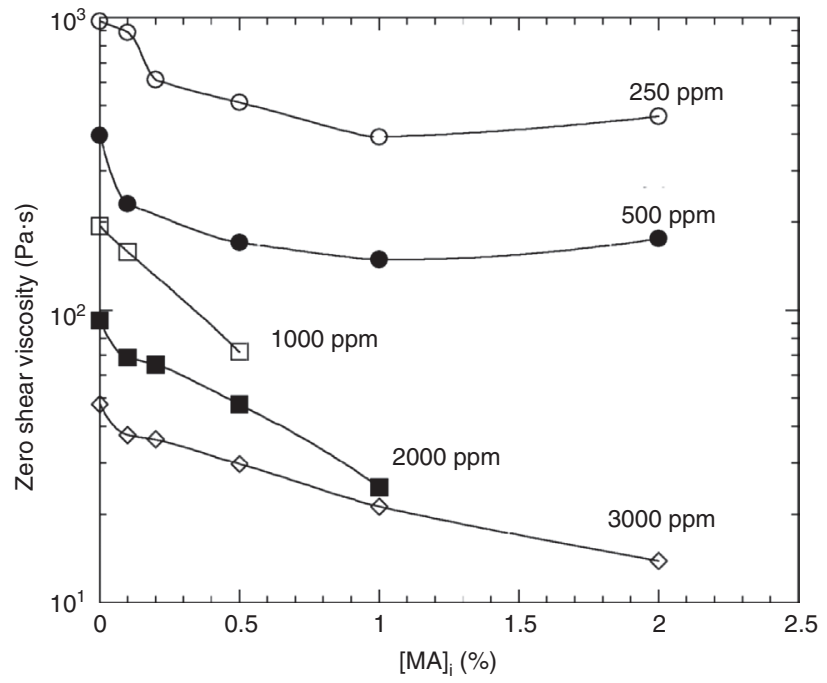

Figure 8 Evolution of zero shear viscosity as function of $[\mathrm{MA}]_{\mathrm{i}}$, where $M A$ is maleic anhydride, for different amounts of peroxide (O: $250 \mathrm{ppm}, \bullet: 500 \mathrm{ppm}, \square: 1000 \mathrm{ppm}, \boldsymbol{\square}: 2000 \mathrm{ppm}, \oslash: 3000 \mathrm{ppm})$ (the lines are just to guide the eyes).

\subsection{Rheological properties}

All of the samples prepared in various conditions of peroxide and MA concentrations were characterized in small amplitude oscillatory shear. Figure 7 shows an example of complex viscosity curves at $3000 \mathrm{ppm}$ peroxide. All other results present the same aspect.

First of all, we can see that the complex viscosity $\left(\eta^{\star}\right)$ of the extruded PP is slightly lower than that of the initial

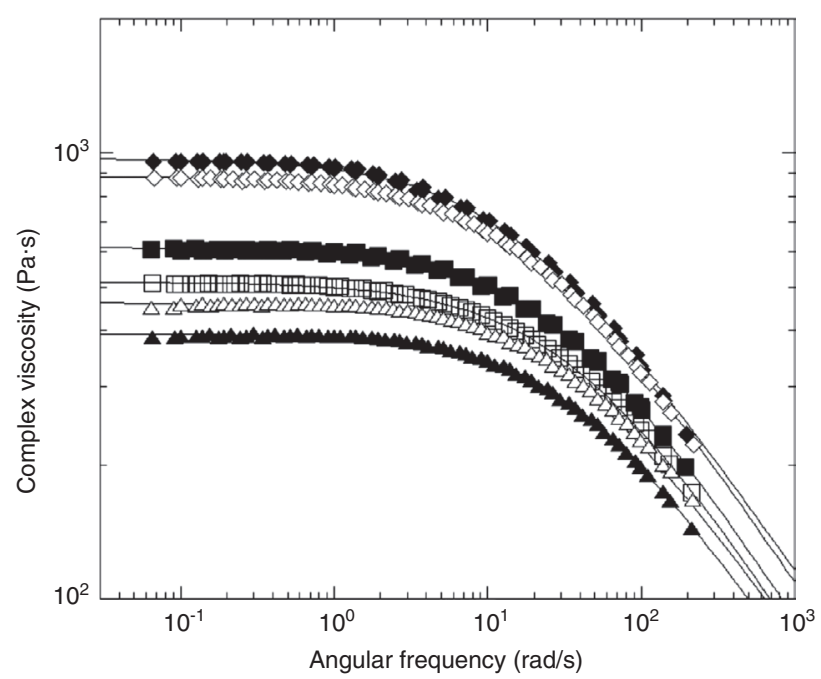

Figure 9 Evolution of complex viscosity with frequency at $250 \mathrm{ppm}$ peroxide for different amounts of $[\mathrm{MA}]_{\mathrm{i}}$, where MA is maleic anhydride ( $: 0 \%, \diamond: 0.1 \%, \square: 0.2 \%, \square: 0.5 \%, \Delta: 1 \%, \Delta: 2 \%)$. Symbols are experimental points, full lines are the fits with Eq. (2). 

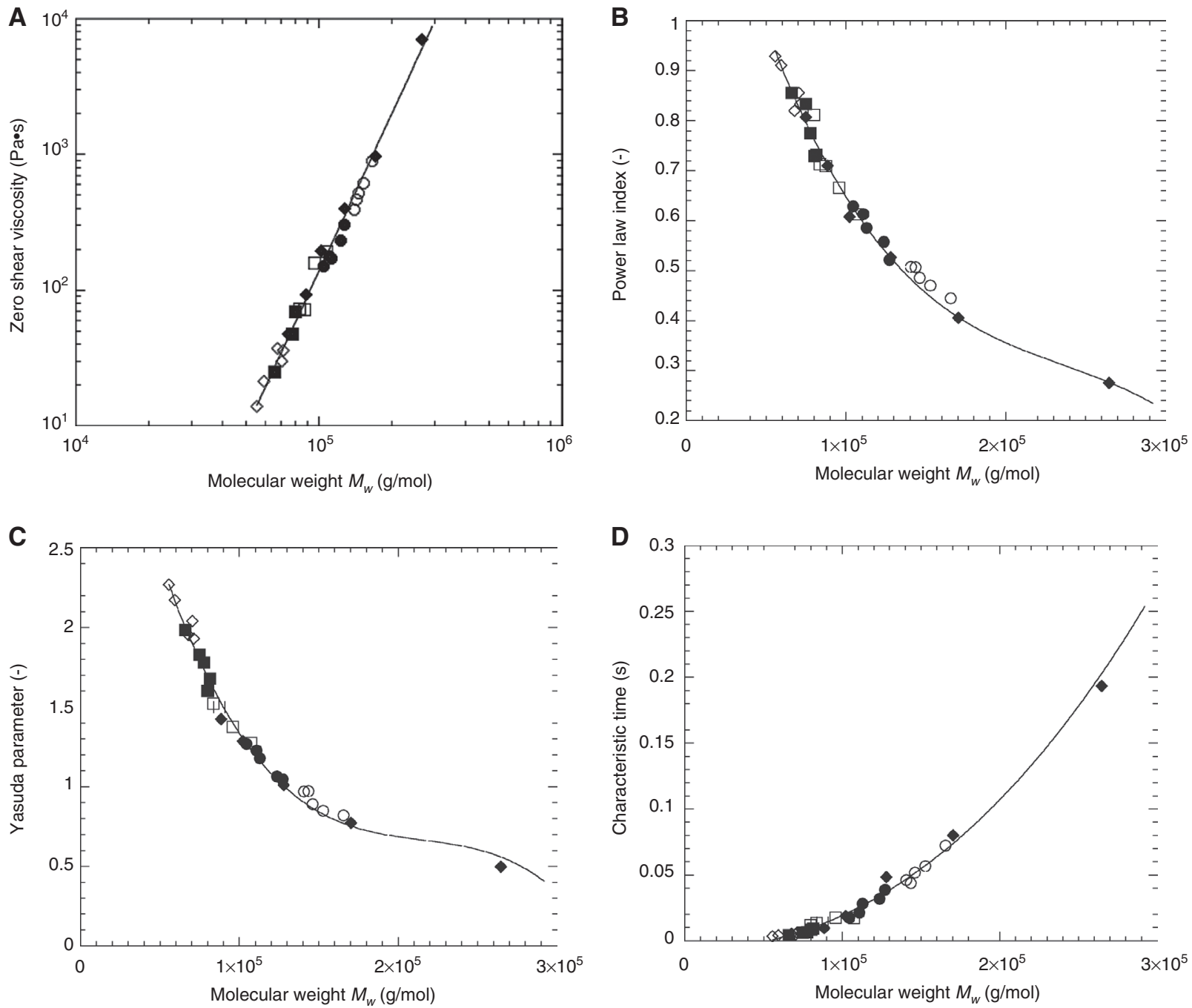

Figure 10 Evolution of the parameters of the Carreau-Yasuda law with the molecular weight, (A) zero shear viscosity, (B) power law index, (C) Yasuda parameter, (D) characteristic time [ $\bullet$ : polypropylene (PP), O: PP+250 ppm peroxide+maleic anhydride (MA), $\bullet: P P+500 \mathrm{ppm}$ peroxide $+M A, \square: P P+1000$ ppm peroxide+MA, $\square: P P+2000$ ppm peroxide+MA, $\diamond: P P+3000$ ppm peroxide+MA]. Symbols are experimental points, full line is a fit with a polynomial expression.

pellets, indicating a slight degradation of the matrix during the extrusion process. As soon as peroxide is introduced, we observe a drastic reduction of the viscosity, here by approximately two decades, resulting essentially from $\beta$-scissions. Moreover, the behavior tends to become more and more Newtonian, except at high frequency, where a shear-thinning behavior may be detected. These results are classical for controlled rheology PP [33, 34]. More interesting is the fact that, at constant peroxide content, the viscosity decreased when the amount of MA increased. This is clearly seen in Figure 8, where the zero shear viscosity $\left(\eta_{0}\right)$ has been plotted as function of [MA] for the various peroxide concentrations. It confirms that, in the range of concentrations we tested, the increase of
MA promotes PP degradation. This effect is more pronounced at high peroxide content.

In the literature, there are only a few papers concerning the rheological behavior of maleated PP obtained by reactive extrusion. Cha and White [7] reported an increase in $\eta^{\star}$ with [MA] $]_{i}$. Similar results, but for a very few number of cases, have also been provided by Oromehie et al. [36] and Machado et al. [13]. Conversely, Ghahari et al. [29] reported results where $\eta^{\star}$ was lower when MA was added to PP and peroxide, but increased with $[\mathrm{MA}]_{\mathrm{i}}$. To our knowledge, the present study is the first systematic investigation on the viscoelastic behavior of maleated PP obtained by reactive extrusion and the results are clear: besides the huge reduction of viscosity induced by the 


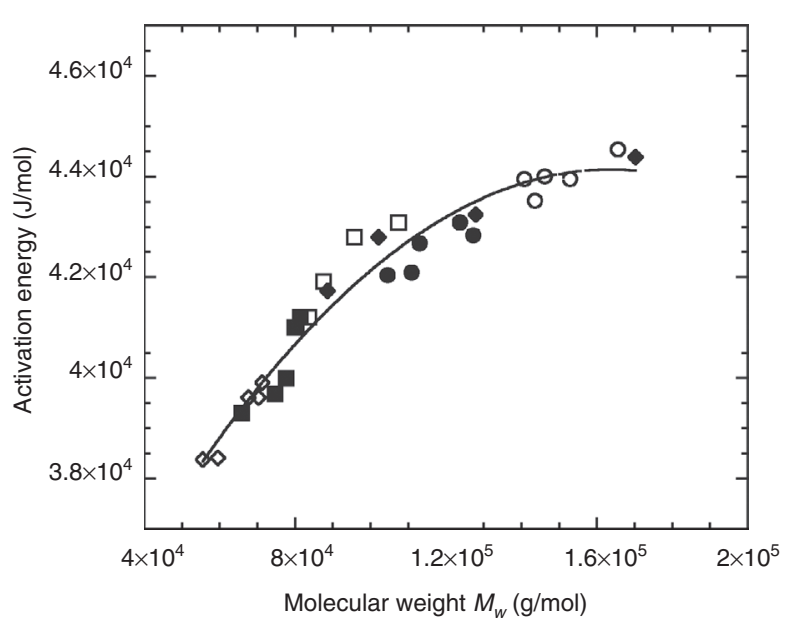

Figure 11 Evolution of the activation energy with the molecular weight (same legend as in Figure 10).

presence of peroxide, MA, at least between $0.1 \mathrm{wt} \%$ and $2 \mathrm{wt} \%$, tends to increase the viscosity drop, but to a lesser extent.

The changes in viscosity are directly related to the changes in molecular weight presented previously. We can fit each viscosity curve of the maleated PP with a Carreau-Yasuda law:

$$
\eta(\omega)=\eta_{0} a_{T}\left[1+\left(\lambda \omega a_{T}\right)^{a}\right]^{\frac{m-1}{a}} \text { with } a_{T}=\exp \left[\frac{E_{a}}{R}\left(\frac{1}{T}-\frac{1}{T_{0}}\right)\right]
$$

where $\eta_{0}$ is the zero shear viscosity, $\lambda$ is a characteristic time, $m$ is the power law index and $a$ is the Yasuda parameter. $a_{T}$ is the temperature shift factor, defined by an Arrhenius law where $E_{a}$ is the activation energy, $R$ the gas constant and $T_{0}$ the reference temperature. An example is given in Figure 9.

The identification of the four parameters $\eta_{0}, \lambda, a$ and $m$ has been done using a Levenberg-Marquardt algorithm. For the different amounts of peroxide and MA, we show in Figure 10 that master curves can be obtained for each of these parameters, if they are plotted as a function of the $M_{w}$. In other words, whatever the grafting conditions (i.e., MA and peroxide concentrations), the rheological behavior is only controlled by the resulting molecular weight. We can see that $\eta_{0}$ increases with $M_{w}$, following a power law with an index of 3.8. When $M_{w}$ decreases, $m$ tends to one and $\lambda$ to zero, indicating a transition from a shearthinning towards a Newtonian behavior.

The $E_{a}$, deduced by time/temperature superposition from data at $180^{\circ} \mathrm{C}, 200^{\circ} \mathrm{C}$ and $220^{\circ} \mathrm{C}$, is shown in Figure 11. Once again, we obtain a master curve when expressed as function of molecular weight. The $E_{a}$ increases monotonically with the molecular weight. The power law or polynomial expressions allowing fit of the various parameters of the viscosity curves are given in the Appendix.

\subsection{Melting and crystallization}

DSC was used to characterize the influence of peroxide and MA contents on the crystallinity and transition temperatures of maleated PP. Figure 12 gives an example of DSC traces for crystallization and melting of the samples at $2 \mathrm{wt} \%[\mathrm{MA}]_{\mathrm{i}}$, for various concentrations of peroxide.

When the concentration increases, we observe an increase in crystallization temperature and a decrease in
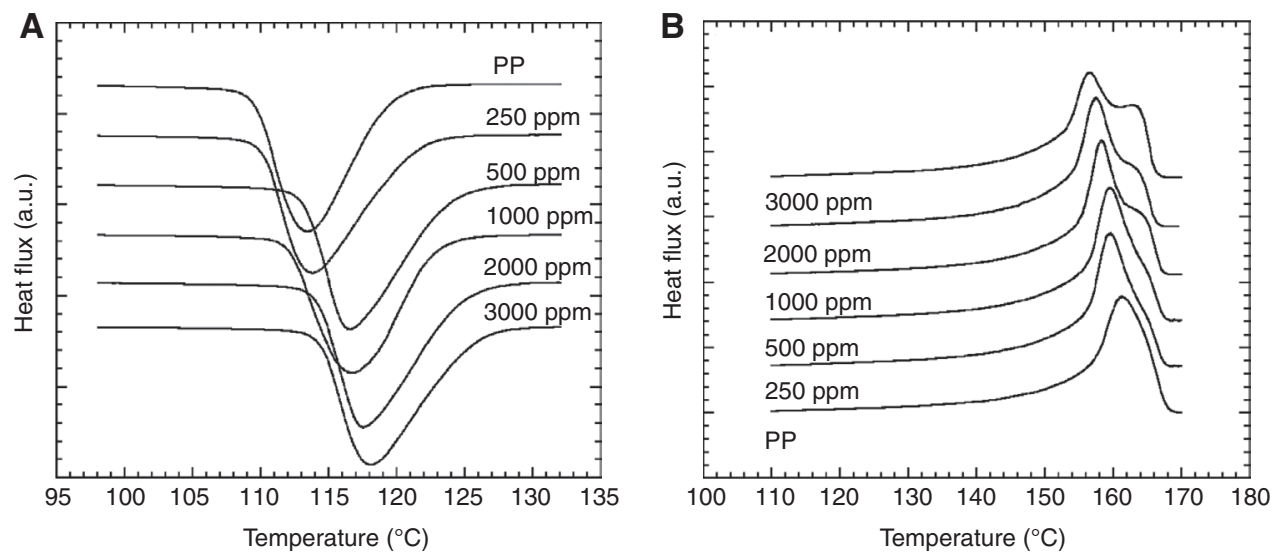

Figure 12 Differential scanning calorimetry (DSC) traces for (A) crystallization and (B) melting for different peroxide contents and $2 \%$ maleic anhydride (MA) (the curves have been shifted vertically for more clarity). 


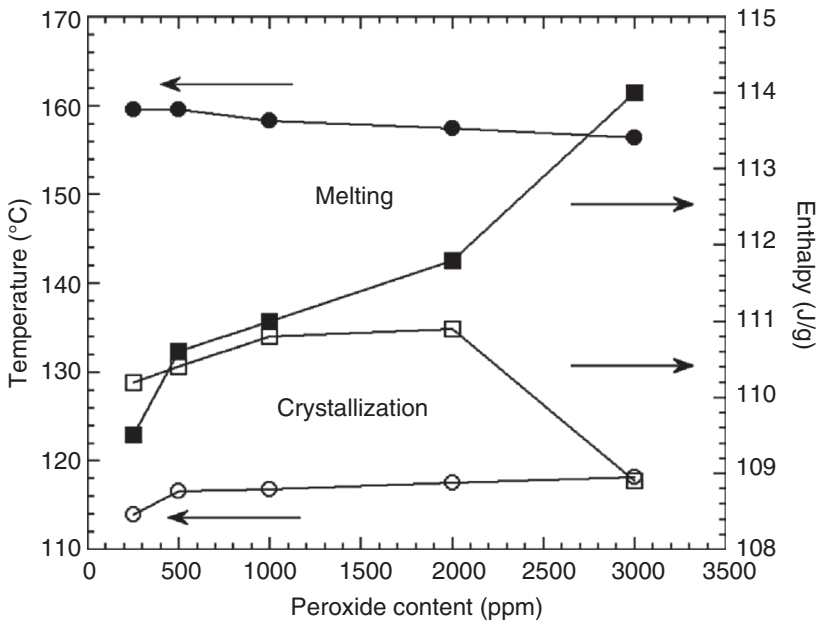

Figure 13 Temperatures $(\mathrm{O}, \bullet)$ and enthalpies $(\square, \square)$ for crystallization and melting for different peroxide contents and $2 \mathrm{wt} \%[\mathrm{MA}]$ where MA is maleic anhydride.

melting temperature, with a shoulder appearing above $1000 \mathrm{ppm}$. When the molecular weight decreases, a double population appears, characteristic of the $\alpha$-phase. The first peak concerns the entities created during isothermal crystallization, whereas the second one is related to the crystallites created during recrystallization and to the reorganization of metastable crystallites [37].

The influence of peroxide content on melting and crystallization temperatures is shown in Figure 13; the enthalpies of melting and crystallization are also plotted. We observe that both enthalpies tend to increase with peroxide content, and are very close, except at 3000 $\mathrm{ppm}$. The effect of $[\mathrm{MA}]_{\mathrm{i}}$ at a fixed peroxide content (2000 ppm) is shown in Figure 14. The results are less clear than

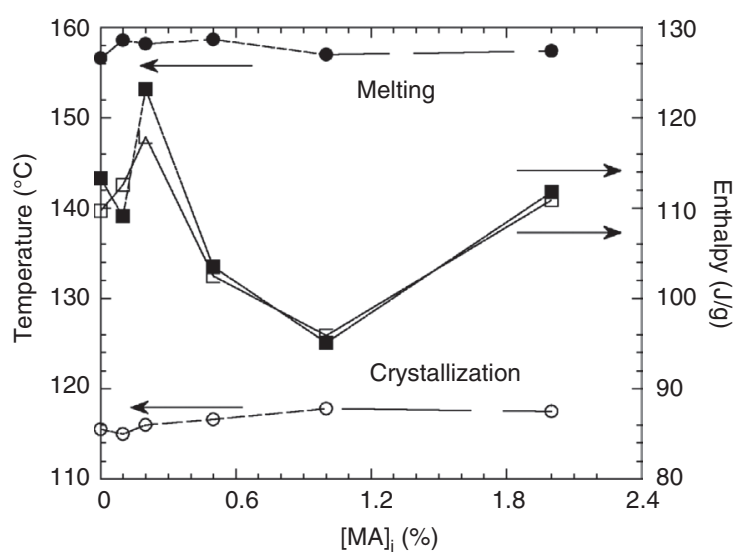

Figure 14 Temperatures $(\mathrm{O}, \bullet)$ and enthalpies $(\square, \square)$ for crystallization and melting for different $[\mathrm{MA}]_{\mathrm{i}}$, where $\mathrm{MA}$ is maleic anhydride, and $2000 \mathrm{ppm}$ peroxide. previously. We always observe a slight increase of melting and crystallization temperatures, but the enthalpies are more erratic, even though the ranges of values are very close for melting and crystallization enthalpies, between $95 \mathrm{~J} / \mathrm{g}$ and $123 \mathrm{~J} / \mathrm{g}$.

For three commercial PP-g-MA with anhydride content between $0.5 \mathrm{wt} \%$ and $3 \mathrm{wt} \%$, Menyhard et al. [37] reported a decrease of melting temperature from $162.7^{\circ} \mathrm{C}$ to $141.5^{\circ} \mathrm{C}$, a decrease of melting enthalpy from $93.5 \mathrm{~J} / \mathrm{g}$ to $50.1 \mathrm{~J} / \mathrm{g}$, a decrease of crystallization temperature from $110.1^{\circ} \mathrm{C}$ to $101.3^{\circ} \mathrm{C}$, and a decrease of crystallization enthalpy from $96.6 \mathrm{~J} / \mathrm{g}$ to $58.5 \mathrm{~J} / \mathrm{g}$, when the percentage of grafted MA was increased. On PP-g-MA prepared by swell grafting, with grafting values between $1.16 \mathrm{wt} \%$ and $4.6 \mathrm{wt} \%$, Ko and Ning [38] noted a slight increase in crystallization temperature from $112^{\circ} \mathrm{C}$ to $114^{\circ} \mathrm{C}$ and a clear decrease of crystallization enthalpy from $99 \mathrm{~J} / \mathrm{g}$ to $84 \mathrm{~J} / \mathrm{g}$. Melting temperature $\left(162^{\circ} \mathrm{C}-163^{\circ} \mathrm{C}\right)$ was not affected, whereas melting enthalpy also decreased from $105 \mathrm{~J} / \mathrm{g}$ to $90 \mathrm{~J} / \mathrm{g}$. Bettini and Agnelli [10] did not observe significant differences between samples prepared by reactive extrusion with peroxide content between $500 \mathrm{ppm}$ and 10,000 ppm and $[\mathrm{MA}]_{\mathrm{i}}$ between $1.5 \mathrm{wt} \%$ and $4 \mathrm{wt} \%$ : melting temperature was between $158.3^{\circ} \mathrm{C}$ and $161.4^{\circ} \mathrm{C}$, crystallization temperature between $112.4^{\circ} \mathrm{C}$ and $117.0^{\circ} \mathrm{C}$, melting enthalpy between $99.2 \mathrm{~J} / \mathrm{g}$ and $105.4 \mathrm{~J} / \mathrm{g}$ and crystallization enthalpy between $93.5 \mathrm{~J} / \mathrm{g}$ and $99.4 \mathrm{~J} / \mathrm{g}$. Similarly, no clear effects of $[\mathrm{MA}]_{\mathrm{i}}$ and peroxide concentration on melting temperature and melting enthalpy were reported by Güldogan et al. [39]. In all cases, these effects were limited, the temperature varying from $162.2^{\circ} \mathrm{C}$ to $165.1^{\circ} \mathrm{C}$ and the enthalpy from $104 \mathrm{~J} / \mathrm{mol}$ to $119 \mathrm{~J} / \mathrm{mol}$. It can thus be concluded that our results are similar to those already reported. However, it is difficult to derive clear conclusions concerning melting and crystallization data, as these parameters depend on the molecular structure, like the location and length of grafted branches, which modify the regularity of the chain structure. This structure depends on the grafting conditions, i.e., peroxide and MA content, but also processing conditions like residence time, temperature or screw profile.

\section{Conclusion}

In this study, we characterized various samples of PP grafted with MA, obtained by reactive extrusion. We showed how the percentage of grafted MA increases with peroxide and MA amounts. The highest GYs (0.4\%) were obtained at high peroxide content and low MA 
concentration. Grafting also influences MFI and molecular weight distribution. Molecular weight decreased with peroxide content, whereas the effect of MA was more reduced. Viscosity also decreased with peroxide and MA amounts. We showed that the viscosity curves can be fitted by Carreau-Yasuda equations, whose parameters only depend on molecular weight, independently of grafted MA. Finally, we showed that the melting and crystallization parameters (temperatures, enthalpies) are modified during grafting, but no general rule can be derived from these results.

Acknowledgments: We thank Arkema company for funding this study and allowing this work to be published.

Received June 12, 2013; accepted September 5, 2013; previously published online October 4, 2013

\section{Appendix A}

Expressions allowing calculation of the parameters of the Carreau-Yasuda law as a function of weight average molecular weight:

Zero shear viscosity:

$\eta_{0}=6.24 \times 10^{-18} M_{w}^{3.87}$

$R^{2}=0.997$

Power law index:

$m=2.30 \times 10^{-18} M_{w}^{3}+2.35 \times 10^{-12} M_{w}^{2}+1.18 \times 10^{-8} M_{w}-0.077 \quad R^{2}=0.995$

Yasuda parameter:

$a=-7.18 \times 10^{-17} M_{w}^{3}+5.09 \times 10^{-11} M_{w}^{2}-1.31 \times 10^{-5} M_{w}+1.526 \quad R^{2}=0.989$

Characteristic time:

$\lambda=-3.49 \times 10^{-16} M_{w}^{3}+2.46 \times 10^{-10} M_{w}^{2}-4.95 \times 10^{-5} M_{w}+4.39 \quad R^{2}=0.987$

Activation energy:

$E_{a}=-4.96 \times 10^{-7} M_{w}^{2}+0.162 M_{w}-30,842 \quad R^{2}=0.947$.

\section{References}

[1] Flat JJ. Nouveaux développements dans le greffage radicalaire sur polypropylène fondu, PhD, University of Strasbourg: Strasbourg, France, 1991.

[2] Garcia-Martinez JM, Laguna O, Collar EP. J. Appl. Polym. Sci. 1998, 68, 483-495.

[3] Ide F, Hasegawa A. J. Appl. Polym. Sci. 1974, 18, 963-974.

[4] Sathe SN, Rao GSS, Devi S. J. Appl. Polym. Sci. 1994, 53, 239-245.

[5] Gaylord NG, Mishra MK. J. Polym. Sci. Polym. Lett. Ed. 1983, 21, 23-30.
[6] Bettini SHP, Agnelli JAM. J. Appl. Polym. Sci. 1999, 74, 247-255.

[7] Cha J, White JL. Polym. Eng. Sci. 2001, 41, 1227-1237.

[8] Garcia Martinez JM, Taranco J, Laguna O, Collar EP. Intern. Polym. Proc. 1994, 9, 346-349.

[9] Hu GH, Flat JJ, Lambla M. Makromol. Chem. Makromol. Symp. 1993, 75, 137-157.

[10] Bettini SHP, Agnelli JAM. J. Appl. Polym. Sci. 2002, 85, 2706-2717.

[11] Shi D, Yang J, Yao Z, Wang Y, Huang H, Jing W, Yin J, Costa G. Polymer 2001, 42, 5549-5557. 
[12] Pruthtikul R, Liewchirakorn P. Adv. Mat. Res., 2010, 93-94, 451-454.

[13] Machado AV, Covas JA, Van Duin M. Polymer 2001, 42, 3649-3655.

[14] Kim BJ, White JL. Intern. Polym. Proc. 1995, 10, 213-220.

[15] Ho RM, Su AC, Wu CH, Chen SI. Polymer 1993, 34, 3264-3269.

[16] Wilkinson AN, Clemens MI, Harding VM. Polymer 2004, 45, 5239-5249.

[17] Shi D, Hu GH, Li RKY. Chem. Eng. Sci. 2006, 61, 3780-3784.

[18] Vergnes B, Berzin F. Plast. Rubber Comp. 2004, 33, 1-7.

[19] Machado AV, Van Duin M, Covas JA. J. Polym. Sci. Part A Polym. Chem. 2000, 38, 3919-3932.

[20] Dorscht BM, Tzoganakis C. J. Appl. Polym. Sci. 2003, 87, 1116-1122.

[21] Henry GRP, Drooghaag X, Rousseaux DDJ, Sclavons M, Devaux J, Marchand-Brynaert J, Carlier V. J. Polym. Sci. Part A Polym. Chem. 2008, 46, 2936-2947.

[22] Baker W, Scott C, Hu GH. Prog. Polym. Sci. 2000, 24, 81-142.

[23] Li Y, Xie XM, Guo BH. Polymer 2001, 42, 3419-3424.

[24] De Roover B, Sclavons M, Carlier V, Devaux J, Legras R, Momatz A. J. Polym. Sci. Part A Polym. Chem. 1995, 33, 829-842.

[25] Zhang R, Zhu Y, Zhang J, Jiang W, Yin J. J. Polym. Sci. Part A Polym. Chem. 2005, 43, 5529-5534.

[26] Heinen W, Rosenmöller CH, Wenzel CB, de Groot HJM, Luftenburg J, van Duin M. Macromol. 1996, 29, 1151-1157.
[27] Yang L, Zhang F, Endo T, Hirotsu T. Macromol. 2003, 36, 4709-4718.

[28] Nachtigall SM, Baumhardt B, Neto R, Mauler RS. Polym. Eng. Sci. 1999, 39, 630-637.

[29] Ghahari SM, Nazokdast H, Assempour H. Intern. Polym. Proc. 2003, 18, 285-290.

[30] Bettini SHP, Agnelli JAM. Polym. Test. 2000, 19, 3-15.

[31] Brown SB. In Reactive Extrusion, Principles, Practice, Xanthos M, Ed., Oxford University Press: New York, 1992.

[32] Sclavons M, Franquinet P, Carlier V, Verfaillie G, Fallais I, Legras R, Laurent M, Thyrion FC. Polymer 2000, 41, 1989-1999.

[33] Tzoganakis C, Vlachopoulos ], Hamielec AE, Shinozaki DM. Polym. Eng. Sci. 1989, 29, 390-396.

[34] Berzin F, Vergnes B, Delamare L. J. Appl. Polym. Sci. 2000, 80, 1243-1252.

[35] Zhu Y, An L, Jiang W. Macromol. 2003, 36, 3714-3720.

[36] Oromehie AR, Hashemi SA, Meldrum IG, Waters DN. Polym. Int. 1997, 42, 117-120.

[37] Menyhard A, Faludi G, Varga J. J. Therm. Anal. Calor. 2008, 93, 937-945.

[38] Ko TM, Ning P. Polym. Eng. Sci. 2000, 40, 1589-1595.

[39] Güldogan Y, Egri S, Rzaev ZMO, Piskin E. J. Appl. Polym. Sci. 2004, 92, 3675-3684. 